\title{
Effects of Water Temperature on Gonad Development in the Cold-Water Fish, Kumgang Fat Minnow Rhynchocypris kumgangensis
}

\author{
Jisu Im, Dongsoo Kong and Sungho Ghil* \\ Department of Life Science, Kyonggi University, Suwon 443-760, Republic of Korea \\ Received October 7, 2015; accepted June 17, 2016
}

\begin{abstract}
Summary Water temperature is one of the most important factors in the survival of aquatic organisms. We investigated the effects of increased water temperature on the physiology of Kumgang fat minnow Rhynchocypris kumgangensis, a small cold-water species of freshwater fish that is endemic to Korea. We examined how organ indices and oocyte histology differed by season and exposure to high water temperatures. Fish were collected from streams in Korea during three different seasons, maintained at the same temperatures at which they were collected for three weeks, and then exposed to either control temperatures reflecting the same conditions from which they were collected $\left(15.0^{\circ} \mathrm{C}\right.$, August; $7.8^{\circ} \mathrm{C}$, November; and $12.3^{\circ} \mathrm{C}$, April) or experimental temperatures that were increased a total of $7^{\circ} \mathrm{C}$ over seven days (to $22.0^{\circ} \mathrm{C}$, August; $14.8^{\circ} \mathrm{C}$, November; and $19.3^{\circ} \mathrm{C}$, April) and maintained at the final temperature for an additional three days. Among the studied organ indices, the gonadosomatic indexes (GSI) in both sexes differed by season, and were significantly decreased by exposure to increased water temperatures during the germ-cell-developing season. The histological features of oocytes also differed by season, and exposure to increased water temperatures during the relevant season markedly attenuated oocyte development. These findings highlight sensitivity of both GSI and oocyte histology on water temperature change, and the possible negative effects of high water temperature on reproduction in Kumgang fat minnow.
\end{abstract}

Key words Biomarker, Freshwater fish, Histology, Oocyte, Organ index.

Water temperature is one of the most important determining factors for fish physiology and ecology (Ficke et al. 2007). The mean global temperature has risen by $0.3-0.4^{\circ} \mathrm{C}$ in the last $60-70$ years (Mann et al. 1998), and global warming is predicted to elevate freshwater temperatures, potentially triggering many changes in the ecology of fish. For example, global warming can drive the movement of fish toward the poles, potentially leading to the extinction of species that cannot find suitable habitats (Parmesan and Yohe 2003, Thomas et al. 2004). Elevated temperatures have been shown to alter the biological diversity of many taxa, including microorganisms, aquatic invertebrates, and fish (Lake et al. 2000). High temperatures are also known to increase the toxicity of common pollutants that decrease fish survival, including organophosphates and heavy metals (Noyes et al. 2009), and to decrease the water concentrations of biologically available oxygen.

Elevated water temperatures can also affect the physiological functions of fish, as their growth and metabolic rates generally increase with temperature. Almost all temperate fish undergo annual growth in the summer, when the food availability is good and the water temperature is optimal for growth (Ficke et al. 2007). However,

*Corresponding author, e-mail: shghil@kgu.ac.kr

DOI: $10.1508 /$ cytologia.81.311 elevated water temperatures may interrupt the completion of vitellogenesis and gonadal development, affect egg quality and survival, cause defects in final maturation, inhibit ovulation (King et al. 2003, Pankhurst et al. 1996), and disrupt the release of reproductive hormones (Miranda et al. 2013, Pankhurst and King 2010).

Kumgang fat minnow Rhynchocypris kumgangensis is a small (average adult length, $c a .8-10 \mathrm{~cm}$ ) freshwater fish belonging to family Cyprinidae. It is a representative cold-water fish, and is endemic to Korea (Yun et al. 2012). The spawning season lasts from May to June (Gwak and Park 2007). Cold-water fish are known to be generally more vulnerable to changes in water temperature (Stitt et al. 2014), and it is possible that global warming may threaten their survival in particular. Therefore, we believe that it will be important to undertake long-term monitoring of physiological changes among such fish, and to develop biomarkers that can evaluate their physiology (e.g., by monitoring stress and reproductive ability). In a previous study, we cloned the heat shock protein 70 gene from Kumgan fat minnow as a potential biomarker for high-water-temperature stress, and showed that its expression was significantly increased by elevated water temperature (Im and Ghil 2013).

The aims of this study were: (1) to analyze the organ indices and oocyte histology of Kumgan fat minnow by 
season; (2) to analyze the effect of high temperature on organ indices and oocyte histology; and (3) to evaluate whether organ indices and oocyte histology could be used as biomarkers for the physiological changes of fish exposed to high water temperatures.

\section{Materials and methods}

\section{Fish collection and water temperature control}

Adult Kumgang fat minnow individuals were collected from streams in Hwacheon-gun and Inje-gun (Gangwon-do, Republic of Korea) in August, November, and April. After collection, the fish were transferred to a laboratory tank that contained a circulation filter and a cooling system that held the water at the same temperature under which the fish were collected (i.e., $15.0^{\circ} \mathrm{C}$ in August, $7.8^{\circ} \mathrm{C}$ in November, and $12.3^{\circ} \mathrm{C}$ in April) (Fig. 1a). After three weeks, the fish were divided into two groups: the control group (Con) and the increased water temperature group (Inc). For the control group, the water temperature was maintained as above for $10 \mathrm{~d}$. For the experimental group, the water temperature was increased by $1 \pm 0.5^{\circ} \mathrm{C}$ per day for seven days (i.e., from 15.0 to $22.0^{\circ} \mathrm{C}$ in August, from 7.8 to $14.8^{\circ} \mathrm{C}$ in November, and from 12.3 to $19.3^{\circ} \mathrm{C}$ in April), and then maintained at the maximum temperature for an additional three days.

\section{Tissue collection and organ index measurements}

At the end of the experimental period, the fish in the control and experimental groups were sacrificed by anesthetic overdose (MS222; Sigma-Aldrich, St. Louis, Mo), and their gonads, livers, and gastrointestinal tracts were isolated. The organ indices were measured as follows: the gonads were weighed and the gonadosomatic index (GSI, \%) was calculated as (gonad weight/body

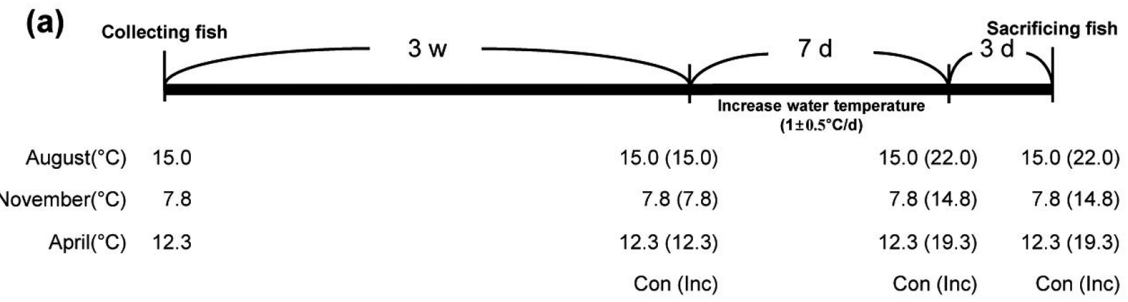

(b)

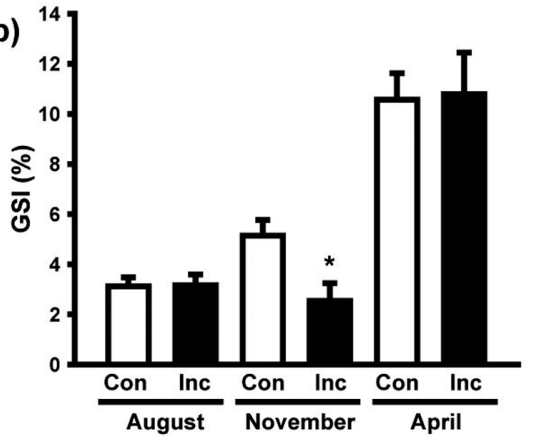

(d)

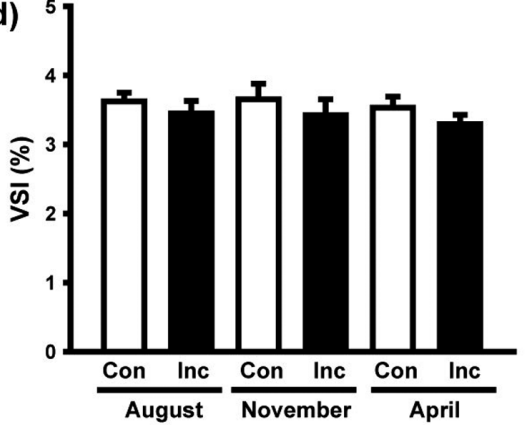

(c)

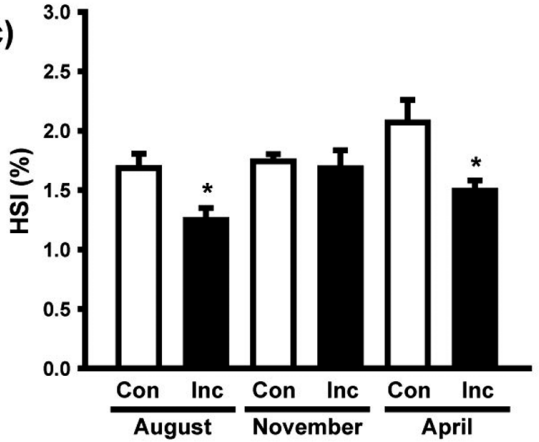

(e)

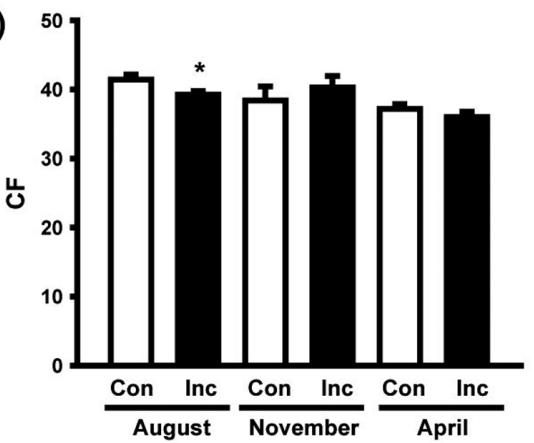

Fig. 1. Changes in the organ indices of female Kumgang fat minnow by season and following exposure to increased water temperatures. (a) In the indicated months, female fish were collected and transferred to fish tanks held at the indicated temperatures. After three weeks, the fish were divided into two groups: the control group (Con; maintained at the collection temperature) and the increased-water-temperature experimental group (Inc; temperature increased by $1 \pm 0.5^{\circ} \mathrm{C}$ a day for seven days and kept at the maximal temperature for an additional three days). At the end of the experimental period, the fish were sacrificed, organs were isolated, and organ indices were measured. (b-e) GSI (b), HSI (c), VSI (d), and CF (e) were calculated as described in the Materials and methods section. Values are presented as the mean \pm S.E.M. $(n=7-17)$; $* p<0.05$ (paired $t$-test) compared to the same-month control. 
weight $\times 100$; the livers were weighed and the hepatosomatic index (HSI, \%) was calculated as (liver weight/ body weight) $\times 100$; and the gastrointestinal tracts were weighed and the viscerosomatic index (VSI, \%) was calculated as (visceral weight/body weight $) \times 100$. The condition factor $(\mathrm{CF})$ was calculated as ((body weight $\times 100) /$ (width $\times$ height $\times$ length)).

\section{Histological study of oocytes}

The isolated ovaries and livers were fixed with $4 \%$ paraformaldehyde for $24 \mathrm{~h}$, embedded in paraffin, sectioned with a microtome, subjected to hematoxylin-eosin (HE) staining, and observed through a light microscope (Olympus BX51TF, Tokyo, Japan). Oocyte development was evaluated by counting the number of oocytes in each developmental stage (see the Results section for a description of the stages). Oocyte diameters were measured using the Axio Vision LE software (Carl Zeiss, Oberkochen, Germany).

\section{Statistical analysis}

Results were expressed as mean values \pm standard error (mean \pm S.E.). Statistical analysis was performed by $t$-test. A level of $p<0.05$ was considered to be significant.
Results

Organ indices of Kumgang fat minnow by season and following elevation of water temperature

First, we studied wild female Kumgang fat minnow. We analyzed the organ indices (GSI, HSI, and VSI) and $\mathrm{CF}$ by season, and then examined the changes in these measures following exposure to increased water temperatures. In control fish, the GSI values were highest and lowest before (April) and after (August) the spawning period (which spans May to June), and intermediate in November (though significantly higher than in August) (Fig. 1b). In the experimental group, exposure to increased water temperatures significantly attenuated the GSI in November, but not in August or April (Fig. 1b). HSI and CF did not differ by season, but were slightly but statistically significantly decreased by elevated water temperatures in August and April (Fig. 1c) and in August (Fig. 1e), respectively. VSI was not significantly affected by the season or elevated water temperature (Fig. 1d).

Next, we investigated the effects of increased water temperature on the organ indices and CF of male Kumgang fat minnow. Similar to our results in females, only the GSI levels were affected by season in control male fish (Fig. 2a). Elevated water temperature significantly (a)

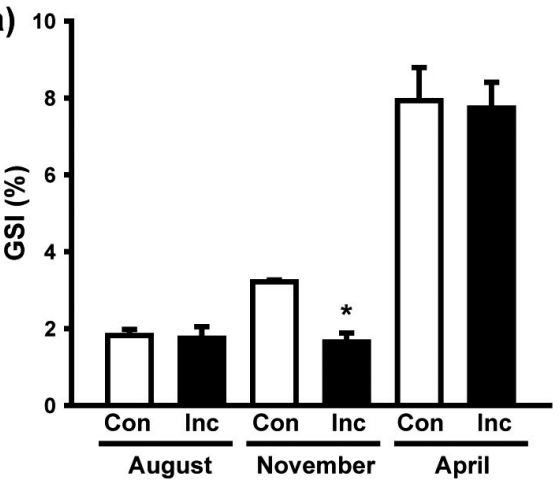

(b)

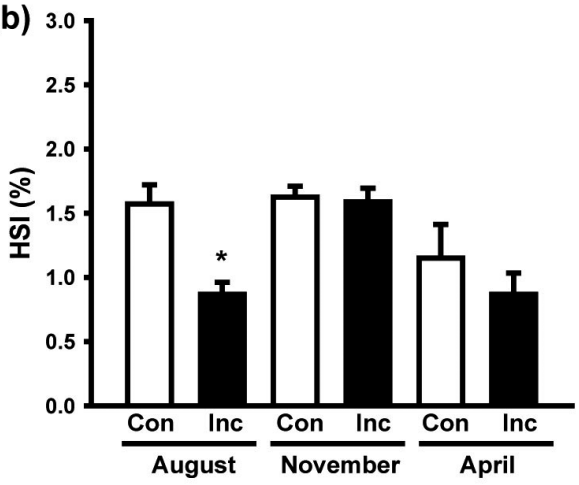

(c)

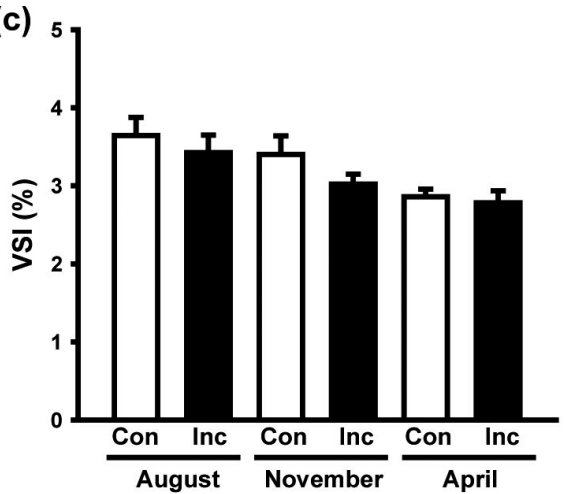

(d)

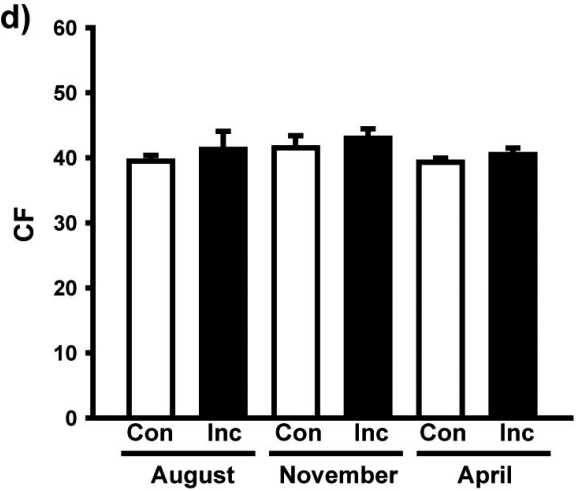

Fig. 2. Changes in the organ indices of male Kumgang fat minnow by season and following exposure to increased water temperatures. In the indicated months, male fish were collected and divided into the control (Con) and experimental (Inc) groups, and treated as described in the legend to Fig. 1. At the end of the experimental period, organs were isolated and GSI (a), HSI (b), VSI (c), and CF (d) were calculated. Values are given as the mean \pm S.E.M. $(n=7-12) ;{ }^{*} p<0.05$ (paired $t$-test) compared to the control in the same month. 
decreased the GSI and HSI values obtained in November and August, respectively, among males (Fig. 2a and b), and the VSI and CF were unaffected by season or increased water temperature (Fig. $2 \mathrm{c}$ and d).

Since elevated temperatures were associated with significant reductions in the HSI values of both sexes in August, we investigated whether the higher temperatures induced tissue damage in the liver. However, no difference was observed between the control and experimental groups (data not shown).

Histological features of Kumgang fat minnow oocytes by season and following exposure to increased water temperatures

The oocyte development of fish is generally classified into several stages (Gwak and Park 2007, Quintana et al. 2004, Uribe and Grier 2011). In accordance with previous studies (Gwak and Park 2007, Morris Jr. et al. 2011, Quintana et al. 2004), we herein classified the oocyte development of Kumgang fat minnow into four stages. During early oocyte development, the nucleoli are located at the periphery of the germinal vesicle (GV); oocytes with this characteristic were designated as stage I (Fig. 3a). The diameters of these oocytes ranged from 144.9 to $578.7 \mu \mathrm{m}$, averaging $279.5 \pm 4.2 \mu \mathrm{m}$ (mean \pm S.E.). As oocytes grow, lipid droplets (LDs) accumulate in their cytoplasm; this was considered to be the defining characteristic of stage II oocytes (Fig. 3a and b). During this stage, LDs initially appeared at the periphery, and then increased in number and size as the oocytes grew. The stage II oocytes ranged from 460.9 to $1000.6 \mu \mathrm{m}$ in diameter, averaging $633.8 \pm 9.6 \mu \mathrm{m}$. As development proceeded, the oocytes increased significantly in size, and many LDs were observed (Fig. $3 c)$. These oocytes, which were designated as stage III, also contained a granular acidophilic yolk containing many yolk granules (Morris Jr. et al. 2011, Quintana et al. 2004) at the nuclear periphery and had a thick zona radiata (i.e., surrounding layers of oocytes), which is generally observed during vitellogenesis (Jiang et al. 2010, Shabanipour and Hossayni 2010). The stage III oocytes ranged from 769.4 to $2315.3 \mu \mathrm{m}$ in diameter, averaging $1271.8 \pm 14.7 \mu \mathrm{m}$. The full-grown oocytes (stage IV oocytes) had very large acidophilic yolks that completely blocked the penetration of the paraffin wax into the cytoplasm (Fig. 3c). The stage IV oocytes ranged from 1374.4 to $4020.2 \mu \mathrm{m}$ in diameter, averaging $2539.4 \pm 70.1 \mu \mathrm{m}$. In August (Fig. 3a and d) and November (Fig. 3b and d), almost all of the oocytes were in stages I and II (in August, 89.3\%; in November, 88.1\%). Before the spawning season (in April; Fig. 3c and d), stage III and IV oocytes were more abundant (55.7\%) compared to August and November.

We next investigated whether experimental elevation of the water temperature could attenuate oocyte development. In August and April (Fig. 4a and c), the elevated water temperatures did not affect the distribution of oocytes across the various developmental stages. Notably,

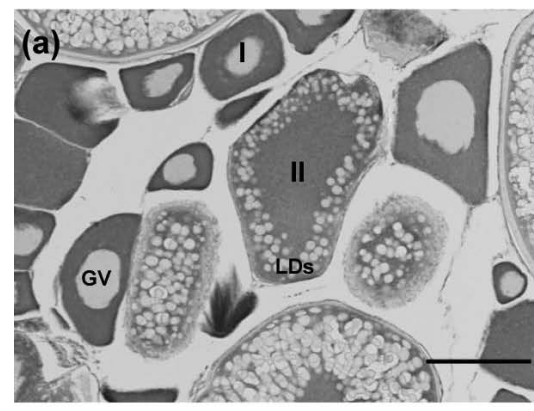

(c)

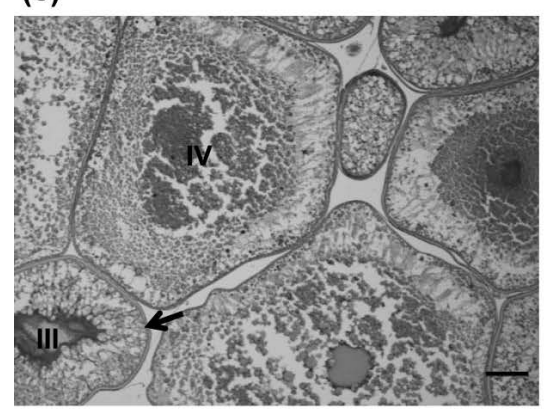

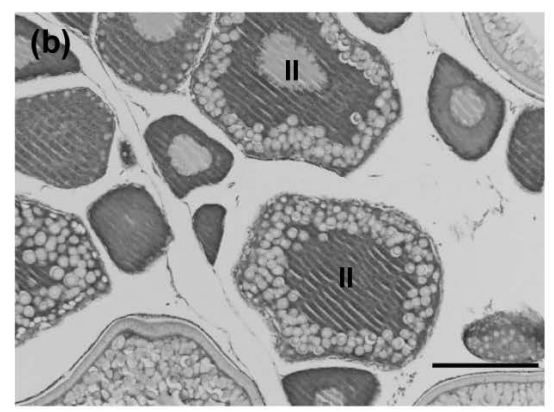

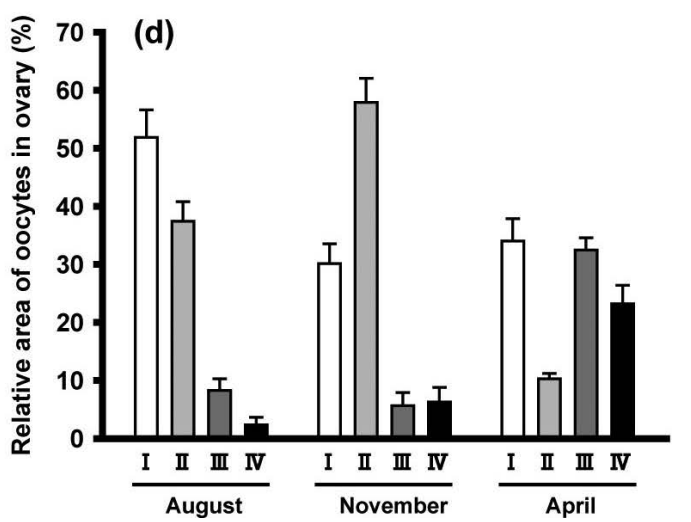

Fig. 3. Histological features of ovaries by season. Control female fish were collected in August (a), November (b), and April (c), and ovaries were isolated and subjected to HE staining. Abbreviations and symbols: I, II, III, and IV represent the stages of oocyte development discussed in the Results section; the arrow indicates the zona radiata; and the scale bar $=200 \mu \mathrm{m}$. (d) The oocytes at each developmental stage were counted, and the relative distributions were calculated for the indicated months. Values are presented as the mean \pm S.E.M. Abbreviations: GV, germinal vesicle; LD, lipid droplets. 
(a)

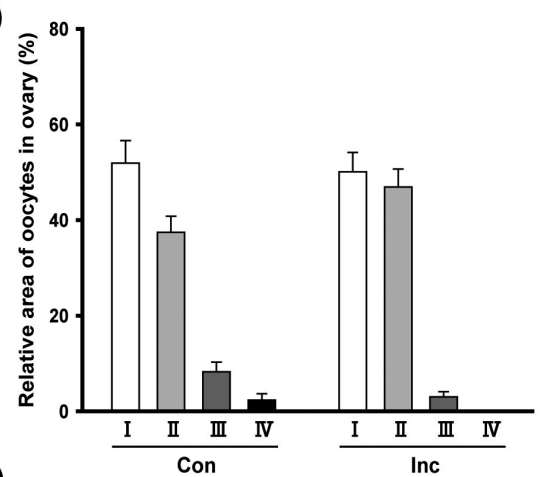

(b)

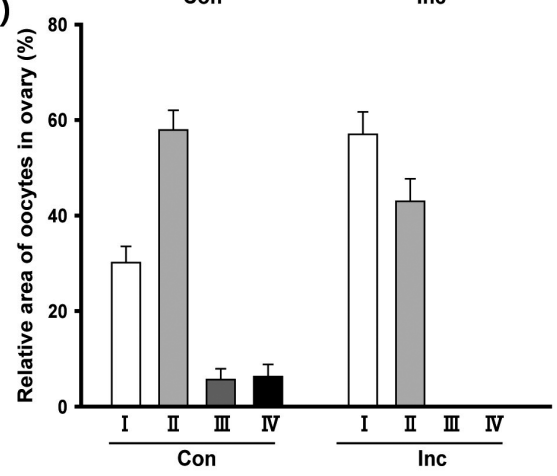

(c)

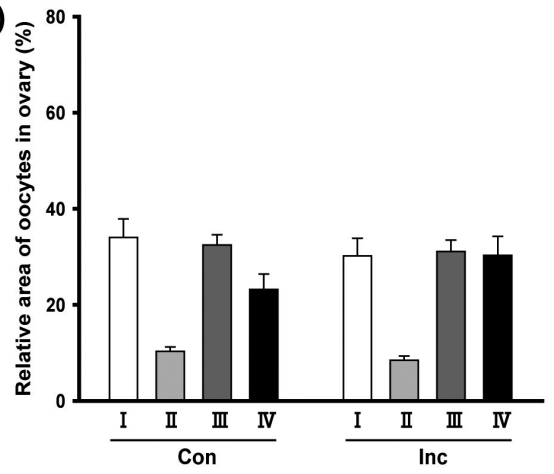

Fig. 4. Effects of increased water temperatures on oocyte development. Female fish were collected in August (a), November (b), and April (c), divided into the control (Con) and experimental (Inc) groups, and treated as described in the legend to Fig. 1. At the end of the experimental period, ovaries were isolated and subjected to HE staining. The distribution of oocytes at each developmental stage was determined as described in the legend to Fig. 3. Values are given as the mean \pm S.E.M.

however, elevation of the water temperature inhibited oocyte development in November (Fig. 4b); the number of stage I oocytes was increased, and no stage III or IV oocytes were observed.

Finally, we investigated oocyte diameter by season and following elevation of the water temperature. In control fish, the seasonal changes in oocyte diameter were similar to those observed for the GSI (Fig. 5), with oocyte diameters peaking in April, reaching the minimum in August, and showing an intermediate value in November. Exposure to higher water temperatures reduced the average diameter of the oocytes from $843.1 \pm 36.9$ to $504.7 \pm 26.8 \mu \mathrm{m}$ in November; in contrast, no temperature-induced change was observed in August or April.

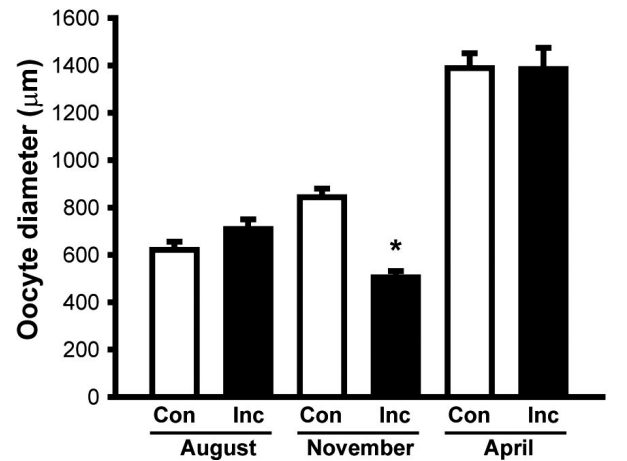

Fig. 5. Changes in oocyte diameter by season and following exposure to increased water temperatures. Female fish were collected in the indicated months, divided into control (Con) and experimental (Inc) groups, and treated as described in the legend to Fig. 1. At the end of the experimental period, ovaries were isolated and subjected to HE staining, and oocyte diameters were measured. Values are presented as the mean \pm S.E.M.; $* p<0.001$ (paired $t$-test) compared to the same-month control.

\section{Discussion}

Different seasons and an increased water temperature were both associated with considerable GSI changes in both sexes of Kumgang fat minnow, as well as in the oocyte morphologies of female fish. Exposure to the higher temperature during the germ-cell-developing season significantly reduced GSI and attenuated oocyte development, suggesting that water temperature is an important factor for gonadal development in both sexes. This is consistent with several lines of existing evidence suggesting that changes in water temperature can affect gonadal development in fish. For example, exposure to high or low water temperatures was shown to attenuate gonadal maturation in both sexes of the pike-perch, Sander lucioperca (Hermelink et al. 2011). High water temperatures reportedly damaged oocyte surfaces and reduced oocyte size via decreased levels of plasma gonadal hormone in the salmon, Salmo salar (King et al. 2003). In the pejerrey, Odontesthes bonariensis, elevated temperatures reduced hormone levels in the brainpituitary-gonad axis, leading to gonadal regression and impaired spawning (Miranda et al. 2013). Finally, in the European bullhead, Cottus gobio, a $4^{\circ} \mathrm{C}$ increase in water temperature accelerated oocyte maturation, while an $8^{\circ} \mathrm{C}$ rise disrupted its maturation (Dorts et al. 2012).

In our study, elevation of the water temperature attenuated GSI and oocyte development only in November, during the germ-cell-developing season, but not in August or April. Although the histology of oocytes in the experimental group appeared normal in August and April, we cannot exclude the possibility that ovulation and/or gamete quality could have been affected by increased water temperatures during these seasons. For example, elevation of water temperature induced failures in ovulation and egg production among rainbow 
trout (Pankhurst et al. 1996). Spawning activity and the mRNA expression levels of gonadotropins were impaired by elevated water temperatures in both sexes of the pejerrey (Elisio et al. 2012, Soria et al. 2008). Water temperature elevation during the spawning season increased the proportion of unfertilized and abnormally dividing eggs in the whitefish, Coregonus lavaretus, leading to increased mortality of early-stage fish (Cingi et al. 2010). Early in their life cycles, fish are highly sensitive to various environmental factors, including mineral balances, pH, heavy metals, and oxygen (Finn 2007). Finally, water temperature was found to act as an important determinant of gamete quality in the European grayling, Thymallus thymallus (Lahnsteiner and Kletzl 2012, Lahnsteiner and Mansour 2012). These authors showed that the highest-quality gametes were produced under natural water temperature conditions, whereas elevated water temperatures significantly decreased the percentages of motile spermatozoa in males, ovulating females, and embryos that developed to the eyed stage. The effects of elevated water temperatures on gamete quality were more pronounced in females than in males.

We herein found that increased water temperatures were associated with reductions in HSI for August and April in both sexes (Figs. 1c and 2b), but we did not observe any liver damage in high-temperature-exposed fish. HSI has been shown to be affected by the levels of various hormones, including E2 and insulin-like growth factor-1 (IGF-1). Since E2 treatment has been found to increase HSI and vitellogenin synthesis in numerous fish species (Osachoff et al. 2013, Pandelides et al. 2014, Park et al. 2010) and elevated water temperatures impair E2 secretion (King et al. 2003), we speculate that the elevated water temperature might have attenuated E2 secretion in our system, leading to the observed reductions in HSI. Long-term exposure to warm temperatures was previously shown to decrease IGF-1 levels, HSI values, and growth among juveniles of the southern flounder, Paralichthys lethostigma (Luckenbach et al. 2007). IGF1 plays important roles in the differentiation, development, growth, and reproduction of fish, and has been implicated in the development of various organs, including the gonads, gills, kidney, cartilage, pancreas, and muscles (Reinecke 2010). Therefore, we speculate that the high-temperature-induced reductions of HSI seen in the present work may reflect the disruption of various hormonal regulation pathways.

In conclusion, we herein show that exposure to elevated water temperature significantly inhibits gonadal development in both sexes of Kumgang fat minnow with oocyte development showing marked effects. Global warming can be associated with long-term increases in water temperature, potentially affecting the quality and biodiversity of aquatic environments. Kumgang fat minnow is a representative cold-water fish, and thus would be expected to be affected by elevated temperatures.
Indeed, our present results suggest that global warming could negatively affect the reproduction of this species. To support conservation, therefore, we need new biomarkers for the long-term monitoring of stress and reproduction in this fish species. Based on our present results, we believe that GSI and oocyte histology may be valuable biomarkers for the conservation of Kumgang fat minnow. Furthermore, assessment of stress protein expression and hormone levels could be evaluated for this purpose in the future.

\section{Acknowledgements}

This research was supported by the Basic Science Research Program through the National Research Foundation of Korea (NRF) funded by the Ministry of Education, Science and Technology (NRF2012R1A1A2005207); the Bio-industry Technology Development Program (312027-3), Ministry of Agriculture, Food and Rural Affairs; and Han-River Drainage Basin Management Committee, Korea.

\section{References}

Cingi, S., Keinanen, M. and Vuorinen, P. J. 2010. Elevated water temperature impairs fertilization and embryonic development of whitefish Coregonus lavaretus. J. Fish Biol. 76: 502-521.

Dorts, J., Grenouillet, G., Douxfils, J., Mandiki, S. N., Milla, S., Silvestre, F. and Kestemont, P. 2012. Evidence that elevated water temperature affects the reproductive physiology of the European bullhead Cottus gobio. Fish Physiol. Biochem. 38: 389-399.

Elisio, M., Chalde, T. and Miranda, L. A. 2012. Effects of short periods of warm water fluctuations on reproductive endocrine axis of the pejerrey (Odontesthes bonariensis) spawning. Comp. Biochem. Physiol. A Mol. Integr. Physiol. 163: 47-55.

Ficke, A. D., Myrick, C. A. and Hansen, L. J. 2007. Potential impacts of global climate change on freshwater fisheries. Rev. Fish Biol. Fish. 17: 581-613.

Finn, R. N. 2007. The physiology and toxicology of salmonid eggs and larvae in relation to water quality criteria. Aquat. Toxicol. 81: 337-354.

Gwak, J. and Park, J. 2007. Structure of oocyte surface in two Korean Minnow species, Rhynchocypris kumgangensis and R. oxycephalus (Pisces: Cyprinidae). Korean J. Ichthyol. 19: 16-23.

Hermelink, B., Wuertz, S., Trubiroha, A., Rennert, B., Kloas, W. and Schulz, C. 2011. Influence of temperature on puberty and maturation of pikeperch, Sander lucioperca. Gen. Comp. Endocrinol. 172: 282-292.

Im, J. and Ghil, S. 2013. Cloning of heat shock protein 70 and its expression profile under an increase of water temperature in Rhynchocypris kungangensis. J. Korean Soc. Water Environ. 29: 232-238.

Jiang, Y. Q., Zhang, T. T. and Yang, W. X. 2010. Formation of zona radiata and ultrastructural analysis of egg envelope during oogenesis of Chinese perch Siniperca chuatsi. Micron 41: 7-14.

King, H. R., Pankhurst, N. W., Watts, M. and Pankhurst, P. M. 2003. Effect of elevated summer temperatures on gonadal steroid production, vitellogenesis and egg quality in female Atlantic salmon. J. Fish Biol. 63: 153-167.

Lahnsteiner, F. and Kletzl, M. 2012. The effect of water temperature on gamete maturation and gamete quality in the European grayling (Thymalus thymallus) based on experimental data and on 
data from wild populations. Fish Physiol. Biochem. 38: 455-467.

Lahnsteiner, F. and Mansour, N. 2012. The effect of temperature on sperm motility and enzymatic activity in brown trout Salmo trutta, burbot Lota lota and grayling Thymallus thymallus. J. Fish Biol. 81: 197-209.

Lake, P. S., Palmer, M. A., Biro, P., Cole, J., Covich, A. P., Dahm, C., Gibert, J., Goedkoop, W., Martens, K. and Verhoeven, J. 2000. Global change and the biodiversity of freshwater ecosystems: Impacts on linkages between above-sediment and sediment biota. Bioscience 50: 1099-1107.

Luckenbach, J. A., Murashige, R., Daniels, H. V., Godwin, J. and Borski, R. J. 2007. Temperature affects insulin-like growth factor I and growth of juvenile southern flounder, Paralichthys lethostigma. Comp. Biochem. Physiol. A Mol. Integr. Physiol. 146: 95-104.

Mann, M. E., Bradley, R. S. and Hughes, M. K. 1998. Global-scale temperature patterns and climate forcing over the past six centuries. Nature 392: 779-787.

Miranda, L. A., Chalde, T., Elisio, M. and Strussmann, C. A. 2013. Effects of global warming on fish reproductive endocrine axis, with special emphasis in pejerrey Odontesthes bonariensis. Gen. Comp. Endocrinol. 192: 45-54.

Morris, J. A. Jr., Sullivan, C. V. and Govoni, J. J. 2011. Oogenesis and spawn formation in the invasive lionfish, Pterois miles and Pterois volitans. Sci. Mar. 75: 147-154.

Noyes, P. D., McElwee, M. K., Miller, H. D., Clark, B. W., Van Tiem, L. A., Walcott, K. C., Erwin, K. N. and Levin, E. D. 2009. The toxicology of climate change: Environmental contaminants in a warming world. Environ. Int. 35: 971-986.

Osachoff, H. L., Shelley, L. K., Furtula, V., van Aggelen, G. C. and Kennedy, C. J. 2013. Induction and recovery of estrogenic effects after short-term $17 \beta$-estradiol exposure in juvenile rainbow trout (Oncorhynchus mykiss). Arch. Environ. Contam. Toxicol. 65: 276-285.

Pandelides, Z., Guchardi, J. and Holdway, D. 2014. Dehydroabietic acid (DHAA) alters metabolic enzyme activity and the effects of $17 \beta$-estradiol in rainbow trout (Oncorhynchus mykiss). Ecotoxicol. Environ. Saf. 101: 168-176.

Pankhurst, N. W. and King, H. R. 2010. Temperature and salmonid reproduction: Implications for aquaculture. J. Fish Biol. 76: 69-85.

Pankhurst, N. W., Purser, G. J., Van Der Kraak, G., Thomas, P. M. and Forteath, G. N. R. 1996. Effect of holding temperature on ovulation, egg fertility, plasma levels of reproductive hormones and in vitro ovarian steroidogenesis in the rainbow trout Oncorhynchus mykiss. Aquaculture 146: 277-290.

Park, C. B., Aoki, J. Y., Lee, J. S., Nagae, M., Lee, Y. D., Sakakura, Y., Hagiwara, A. and Soyano, K. 2010. The effects of 17betaestradiol on various reproductive parameters in the hermaphrodite fish Kryptolebias marmoratus. Aquat. Toxicol. 96: 273-279.

Parmesan, C. and Yohe, G. 2003. A globally coherent fingerprint of climate change impacts across natural systems. Nature 421: $37-42$.

Quintana, L., Silva, A., Berois, N. and Macadar, O. 2004. Temperature induces gonadal maturation and affects electrophysiological sexual maturity indicators in Brachyhypopomus pinnicaudatus from a temperate climate. J. Exp. Biol. 207: 1843-1853.

Reinecke, M. 2010. Influences of the environment on the endocrine and paracrine fish growth hormone-insulin-like growth factor-I system. J. Fish Biol. 76: 1233-1254.

Shabanipour, N. and Hossayni, S. N. 2010. Histological and ultrastructural study of Zona Radiata in oocyte of common carp Cyprinus carpio (Linnaeus 1758). Micron 41: 877-881.

Soria, F. N., Strussmann, C. A. and Miranda, L. A. 2008. High water temperatures impair the reproductive ability of the pejerrey fish Odontesthes bonariensis: Effects on the hypophyseal-gonadal axis. Physiol. Biochem. Zool. 81: 898-905.

Stitt, B. C., Burness, G., Burgomaster, K. A., Currie, S., McDermid, J. L. and Wilson, C. C. 2014. Intraspecific variation in thermal tolerance and acclimation capacity in brook trout (Salvelinus fontinalis): Physiological implications for climate change. Physiol. Biochem. Zool. 87: 15-29.

Thomas, C. D., Cameron, A., Green, R. E., Bakkenes, M., Beaumont, L. J., Collingham, Y. C., Erasmus, B. F., de Siqueira, M. F., Grainger, A., Hannah, L., Hughes, L., Huntley, B., van Jaarsveld, A. S., Midgley, G. F., Miles, L., Ortega-Huerta, M. A., Townsend Peterson, A., Phillips, O. L. and Williams, S. E. 2004. Extinction risk from climate change. Nature 427: 145-148.

Uribe, M. C. and Grier, H. J. 2011. Oogenesis of microlecithal oocytes in the viviparous teleost Heterandria formosa. J. Morphol. 272: 241-257.

Yun, Y. E., Yu, J. N., Kim, S. and Kwak, M. 2012. The complete mitochondrial genome of Kumgang fat minnow Rhynchocypris kumgangensis (Cypriniformes, Leuciscinae) in Korea. Mitochondrial DNA 23: 347-349. 